\title{
Targeting PIK3CG in Combination with Paclitaxel as a Potential Therapeutic Regimen in Claudin-Low Breast Cancer [Corrigendum]
}

Chang J, Hong L, Liu Y. Cancer Manag Res. 2020;12:2641-2651. The authors apologize for this error.

The authors have advised that there is an error in Figure 2E on

page 2646. The correct figure is shown below.
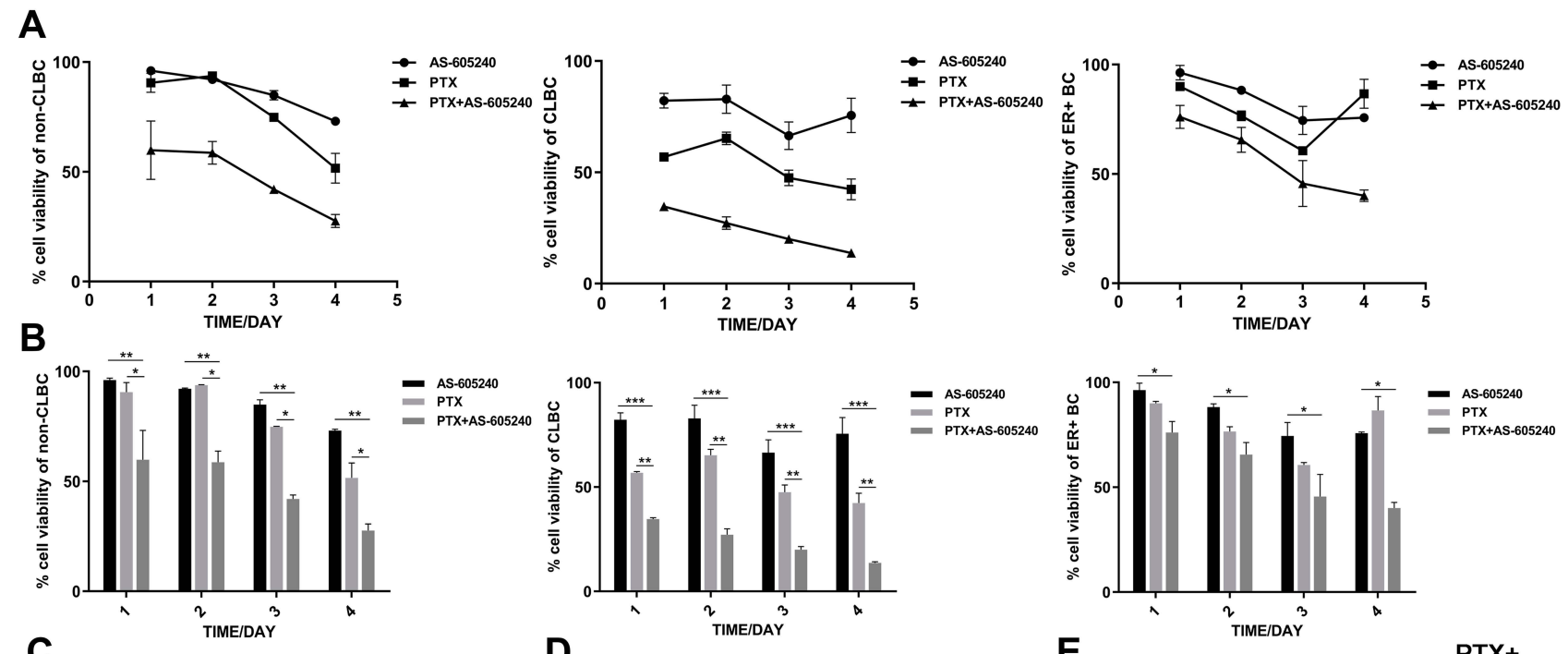

C

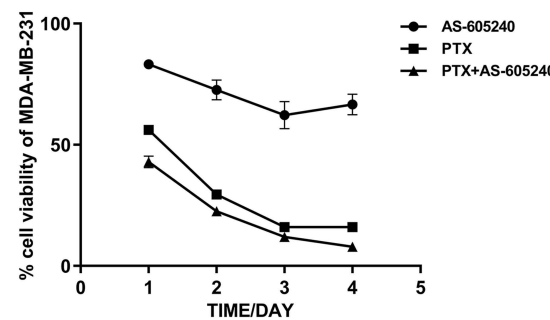

D
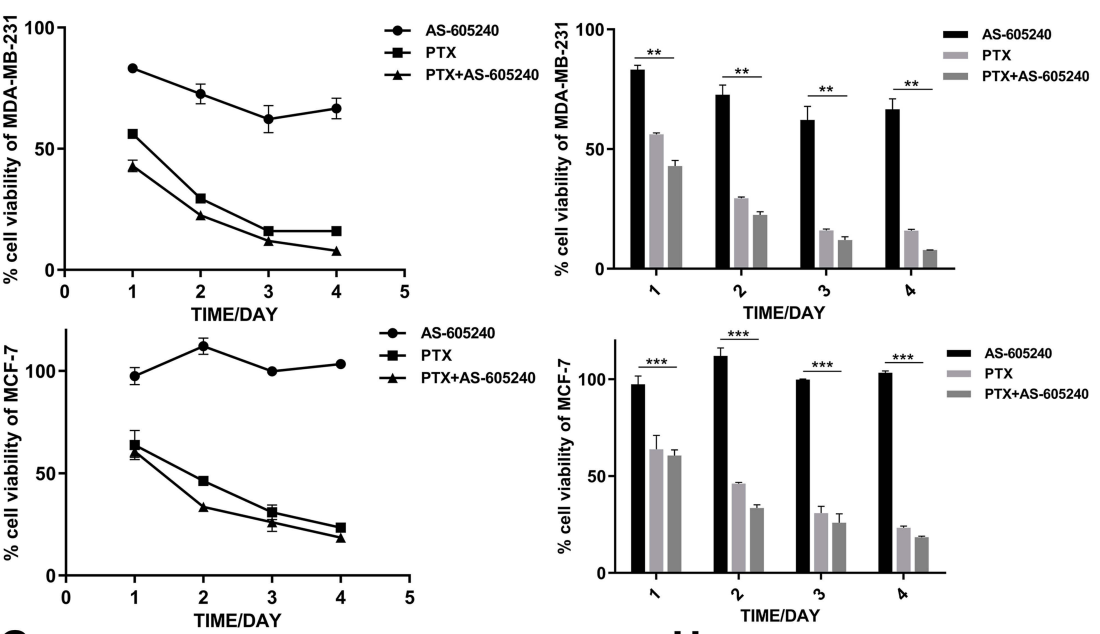

G
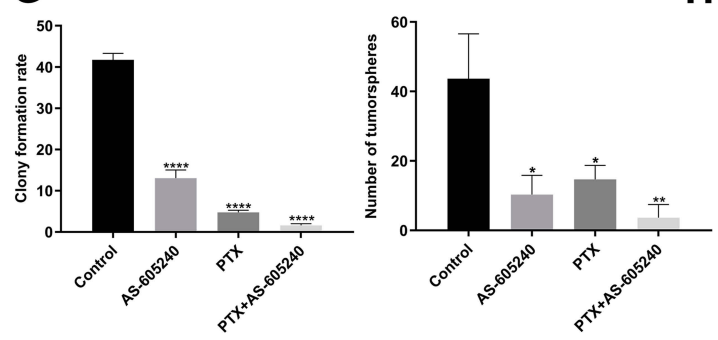

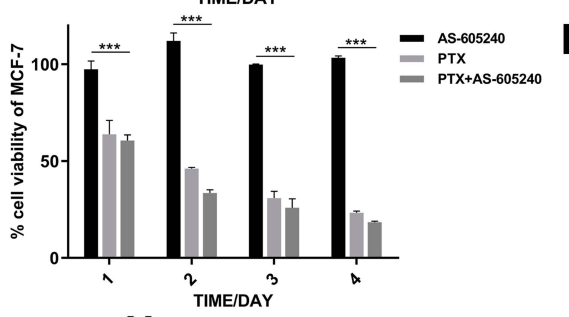

H
E

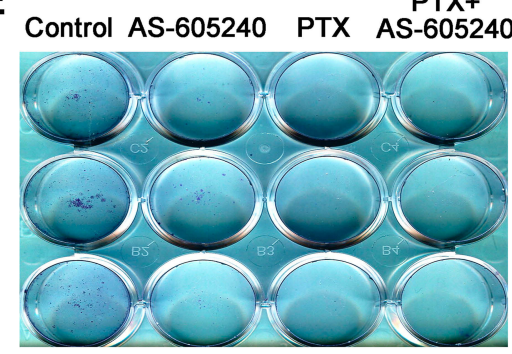

$\mathbf{F}$

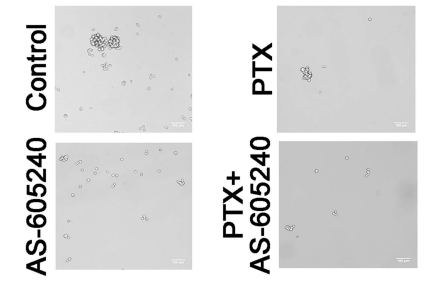

PTX+

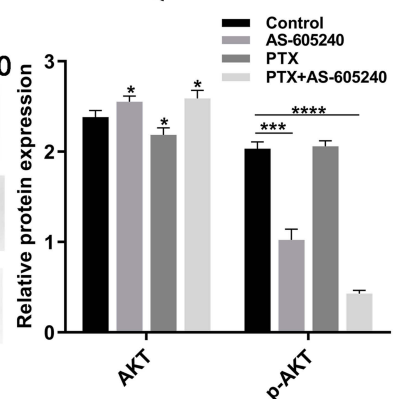




\section{Publish your work in this journal}

Cancer Management and Research is an international, peer-reviewed open access journal focusing on cancer research and the optimal use of preventative and integrated treatment interventions to achieve improved outcomes, enhanced survival and quality of life for the cancer patient.

The manuscript management system is completely online and includes a very quick and fair peer-review system, which is all easy to use. Visit http://www.dovepress.com/testimonials.php to read real quotes from published authors.

Submit your manuscript here: https://www.dovepress.com/cancer-management-and-research-journal 